\title{
A propósito de los orígenes de don Pedro, obispo de Osma (1101-1109)
}

\author{
About the origins of Don Pedro, bishop of Osma (1101-1109)
}

\author{
Juan Pablo Rubio Sadia*
}

\begin{abstract}
RESUMEN
La procedencia del obispo francés Pedro de Osma (1101-1109), el primero tras la restauración diocesana, ha sido objeto de muy diversas consideraciones. De hecho, aparece citado como oriundo de Bourges,

pero también de Béziers, como monje

cluniacense de Auch, pero al mismo tiempo de Aurillac y de Sahagún. En estas páginas vamos a valorar de forma crítica

la base documental existente detrás de cada una de estas aserciones en vistas a esclarecer, en el mayor grado posible, cuál es el verdadero origen (la ciudad y el supuesto monasterio de profesión) del santo patrono de la Iglesia oxomense y dónde se hallan los límites entre la creencia tradicional y el dato documentado.
\end{abstract}

\section{PALABRAS CLAVE}

Pedro de Osma / de Bourges / de Béziers, diócesis de Osma, diócesis de Toledo, monjes cluniacenses, San Orencio de Auch, San Geraldo de Aurillac, Sahagún.

\section{ABSTRACT}

The origin of the French bishop Pedro de Osma (1101-1109), the first one after the diocesan restoration, has been the object of very diverse considerations. In fact, he appears mentioned as native of Bourges, but also of Béziers, as a Cluniac monk of Auch, and at the same time of Aurillac and Sahagún. In these pages we are going to assess in a critical way, the existing documentary base behind each one of these assertions in order to clarify, as much as possible, which is the true origin (the city and the supposed monastery of profession) of the Oxonian Church Patron Saint, and where are the limits between the traditional belief and the documented data.

\section{KEYWORDS}

Pedro of Osma/of Bourges/of Béziers, diocese of Osma, diocese of Toledo, Cluniac monks, Saint Orencio of Auch, Saint Gerald of Aurillac, Sahagún.

* OSB, Abadía de la Santa Cruz del Valle de los Caídos. 


\section{INTRODUCCIÓN}

La figura histórica del primer obispo de la sede oxomense, tras su restauración, es ciertamente enigmática en muchos aspectos. El historiador se halla frente a una lamentable escasez de documentación y, lo que es peor, ante una prolífica y desigual producción historiográfica que, con el transcurso del tiempo, ha propiciado que algunas afirmaciones tan sólo probables hayan alcanzado la categoría de asertos demostrados. Esta misma carencia de fuentes la expresaba en el siglo XVIII el canónigo Juan Loperráez con estos términos: «[...] para escribir la vida del Obispo S. Pedro, solo he hallado las noticias que nos dan las lecciones de los rezos antiguos de esta santa Iglesia, la de Palencia, y el Breviario Asturicense ${ }^{1}$. Al encabezar estas páginas con la alusión a los orígenes del santo obispo Pedro, nuestro propósito es volver a plantear la problemática en torno a dos aspectos muy concretos de su vida: cuál fue su ciudad natal, por un lado, y dónde profesó como monje, en caso de haberlo hecho, por otro. Y ello porque entre las numerosas referencias a este prelado nos encontramos con diversas denominaciones, tales como Pedro de Bourges/Berry o de Béziers, en cuanto a su origen, y como monje de Cluny, Auch/Aurillac o Sahagún. Si consultamos, por ejemplo, el actual Martyrologium Romanum, la noticia del 2 de agosto no alude a su origen, pero sí manifiesta su condición monástica, aunque sin ninguna otra especificación:

9*. Palentiae in Castella Hispaniae, transitas sancti Petri, episcopi Oxomensis, qui primum monachus, deinde archidiaconus Ecclesiae Toletanae, tandem ad sedem Oxomensem elatus est, nuper Maurorum dominatione liberatam, quam pastorali zelo instauravit².

Traigamos todavía dos ejemplos más. El diccionario hagiográfico realizado por los benedictinos ingleses de Ramsgate y publicado en francés por la editorial Brepols (Bélgica), en la voz «Pierre d'Osma», precisa que se trata de un monje benedictino de la observancia cluniacense:

St. év., O.S.B. [=santo obispo de la Orden de san Benito] †1109. Français, moine de Cluny, il était un des nombreux moines clunisiens qui se fixèrent en Espagne en 1050 et en 1130. Archidiacre de Tolède, sous l'archevêque clunisien Bernard de la Sauvetat, il fut nommé évêque d'Osma, en Vieille-Castille, en 1101. II est vénéré comme patron principal de la cathédrale et du diocèse d'Osma ${ }^{3}$.

En cambio, la Bibliotheca Sanctorum nos sorprende con la alusión a su condición de cisterciense (¡debe tratarse de un lapsus!) y a su vida en el monasterio leonés de Sahagún, en cuanto discípulo y compañero del todavía abad Bernardo, futuro arzobispo de Toledo:

1 Loperráez Corvalán, J., Descripción histórica del obispado de Osma, t. I, Madrid, 1788, p. 77.

2 Martyrologium Romanum, Editio Typica, Vaticano, 2001, p. 408. La edición española añade en rojo, al final de la noticia, el año de su óbito (1109). El asterisco $\left(^{*}\right)$, por otra parte, advierte de que se trata de la conmemoración local de un santo antiguo.

${ }_{3}$ Dix mille saints. Dictionnaire hagiographique, Turnhout, 1991, p. 409. 
Monaco cistercense probabilmente del monastero di Saint-Orens di Auch, fu discepolo e compagno di Bernardo, arcivescovo di Toledo, prima nel monastero di Sahugún e poi nella archidiocesi toletana; dopo aver collaborato con lui nella reforma ecclesiastica, che introdusse la reforma gregoriana nella Spagna, ne fu l'arcidiacono a Toledo per alcuni anni. Come altri collaboratori di Bernardo, anche Pietro fu consacrato vescovo nel 1103 ed ebbe assegnata la diocesi di Osma $[\ldots]^{4}$.

Ante un panorama tan confuso y heterogéneo, parece necesario plantearse de nuevo las cuestiones siguientes: ¿cuáles son las fuentes más antiguas y fidedignas que nos hablan de Pedro de Osma? ¿Hasta dónde permiten llegar dichas fuentes respecto a su lugar de procedencia y su itinerario en la vida monástica? Para responder a estos interrogantes vamos a analizar los documentos conocidos y, a partir de ellos, vamos a realizar un balance crítico de las diferentes posturas e interpretaciones posteriores.

Antes, esbozaremos brevemente algunos aspectos del contexto histórico en el que se movió nuestro obispo y que propició su presencia en los territorios del monarca Alfonso VI.

\section{ALGUNAS COORDENADAS HISTÓRICAS}

Comencemos diciendo que las fuentes históricas propiamente contemporáneas a nuestro personaje se reducen a unos pocos diplomas, en los que figura como confirmante. El primero de ellos, con fecha de 2 de enero de 1102, es importante para datar el comienzo de su ministerio episcopal; en él figura como $\mathrm{Pe}$ trus episcopus Osmensis, por detrás de otros eclesiásticos, como el abad Diego de Sahagún y los prelados de Toledo, León y Palencia ${ }^{5}$. Años más tarde, su nombre vuelve a aparecer en otros dos documentos: uno de dudosa autenticidad, que data de 6 de febrero de 11056; y otro falso, de 30 de diciembre de $1107^{7}$. La última referencia cierta es un diploma fechado el 22 de junio de 1109, perteneciente ya al reinado de doña Urraca, en el que se lee Petrus, Oximensis episcopus ${ }^{8}$. Tras su muerte acaecida ese mismo año, la sede fue ocupada por Raimundo de La Sauvetat, a quien algunos historiadores consideran cluniacense ${ }^{9}$, aunque tampoco lo sabemos a ciencia cierta.

${ }^{4}$ Fernández Alonso, J., «Pietro, vescovo di Osma», Bibliotheca Sanctorum, t. X, Roma, 1967, p. 718.

${ }^{5}$ Gambra, A. (ed.), Alfonso VI: Cancillería, curia e imperio. Vol. Il: Colección diplomática, (Fuentes y Estudios de Historia Leonesa 63), León, 1998, doc. 165, p. 431.

6 Ibid., doc. 181, p. 466.

7 Ibid., doc. 190, p. 487.

8 Ruiz AlBI, I. (ed.), La reina Doña Urraca (1109-1126). Cancillería y colección diplomática, (Fuentes y Estudios de Historia Leonesa 102), León, 2003, doc. 1, p. 355.

9 ReILly, B. F., The Kingdom of León-Castilla under King Alfonso VII, 1126-1157, Philadelphia, 1998, p. 244; ID., «Santiago and Saint Denis: The French Presence in Eleventh-Century Spain», The Catholic Historical Review 54 (1968), p. 468; Bısнко, CH. J., «The Abbey of Santa María de Batres and the Cluniac Presente at Toledo from Alfonso VI to Alfonso VII», en Estudios sobre Alfonso VI y la reconquista de Toledo, Actas del II Congreso Internacional de Estudios Mozárabes (Toledo, 20-26 mayo 1985), vol. I, Toledo, 1987, pp. 187-218. 
La presencia de un prelado francés al frente de la Ecclesia oxomensis al inicio de su segunda andadura histórica no es un hecho aislado durante el reinado de Alfonso VI (1065-1109). Como es bien sabido, se inscribe en el doble movimiento de reintegración cultural castellano-leonesa en la Cristiandad latina de su tiempo, y de reforma eclesial, promovida por los pontífices romanos, y favorecida por el auge cluniacense y canonical de los siglos XI y XII. En los estados del rey Alfonso este programa fue diseñado y liderado por Bernardo de La Sauvetat (1086-1125), un cluniacense de San Orencio de Auch (Gascuña), llegado para gobernar el monasterio de Sahagún en 1080, y que en 1086 se convirtió en arzobispo de Toledo. Gracias a este influyente consejero del rey ${ }^{10}$, el nuevo ordenamiento eclesiástico estuvo en manos de prelados procedentes de la otra vertiente de los Pirineos, que habían sido reclutados por él mismo para formar el primer cabildo toledano. En efecto, Bernardo promovió, según cuenta don Rodrigo Jiménez de Rada, un total de nueve obispos franceses: Geraldo de Braga (1096-1108), Jerónimo de Valencia (1098-1102) y Salamanca-Zamora (1102-1120), Mauricio de Coimbra (1099-1108) y Braga (1109-1118), Pedro de Osma (1101-1109), Pedro I de Palencia (11081139), Raimundo de Osma (1109-1124) y Toledo (1125-1152), Pedro de Segovia (1120-1149), Bernardo de Sigüenza (1121-1151) y Santiago (1151-1152), Bernardo de Zamora (1121-1149) ${ }^{11}$. En 1109, año de la muerte del rey y de don Pedro, los protegidos del arzobispo regían en Castilla-León tres sedes (Osma, Palencia y Salamanca $)^{12}$, a las que hay que sumar Segovia y Sigüenza ${ }^{13}$ en los años veinte de ese siglo. Además, con el paso del tiempo, tres de los obispos francos salidos del cabildo toledano (Raimundo de Osma, Juan de Segovia y Cerebruno de Sigüenza) volvieron a Toledo para ocupar la sede primada. Por tanto, el dilatado pontificado de don Bernardo resultó esencial para la organización de la Iglesia secular en los reinos cristianos peninsulares ${ }^{14}$.

Por lo que se refiere al cabildo toledano, al que se incorporó don Pedro y donde llegó a ejercer como arcediano, según veremos más adelante, es incontestable que hubo una presencia cluniacense ${ }^{15}$. El caso más destacado lo constituye Ge-

10 ReILly, B. F., El reino de León y Castilla bajo el rey Alfonso VI (1065-1109), Toledo, 1989, p. 249.

11 Ximenez de Rada, R., Historia de rebus Hispanie sive Historia Gothica, ed. J. Fernández Valverde, (Corpus Christianorum. Continuatio Mediaevalis 72), Turnholt, 1987, lib. VI, cap. XXVI, p. 210, lín. 29-48. Sin embargo, hay que notar que Urraca tuvo cuidado de que tal práctica no se extendiera a los obispados clave de Burgos, León o Astorga, en el corazón del reino según REILLY, B. F., The Kingdom of LeónCastilla under Queen Urraca, 1109-1126, Princeton, 1982, p. 365.

12 ReILLY, The Kingdom of León-Castilla under Queen Urraca, pp. 226-227.

13 Bernardo aprovechó su influencia en la corte real y pontificia para hacer elegir obispos a 8 clérigos que había traído principalmente del sur de Francia y había formado en la Iglesia de Toledo; $R E-$ GLERO DE LA FUENTE, C. M., «Los obispos y sus sedes en los reinos hispánicos occidentales», en VV.AA., La reforma gregoriana y su proyección en la Cristiandad Occidental. Siglos XI-XII, Pamplona, 2006, p. 232. p. 12.

14 Fletcher, R. A., The Episcopate in the Kingdom of León in the Twelfth Century, Oxford, 1978,

15 Las listas de confirmantes de documentos episcopales del cabildo toledano muestran además la mezcla de personajes con nombre hispano y nombre franco, casi por mitad, al igual que sucederá en Palencia o Segovia; RegLeRo dE LA FUENTE, «Los obispos y sus sedes», p. 265. 
raldo, monje venido de San Pedro de Moissac ${ }^{16}$, con la misión de enseñar el desconocido canto romano-franco o "gregoriano"; este santo cluniacense terminaría sus días como metropolitano de la sede de Braga (1096-1108) ${ }^{17}$. Junto a él, suponemos que hubo otros monjes en aquel cabildo, dedicados prioritariamente al culto de la que se ha considerado una «catedral monástica» ${ }^{18}$, al menos en su etapa inicial. Ahora bien, valorar el grado de presencia cluniacense en el cabildo toledano no resulta fácil: debemos evitar tanto el «pan-cluniacismo» ${ }^{19}$, como el exceso inverso, que tiende a hacer de la penetración monástica borgoñona un simple epifenómeno sin mayor repercusión, según Henriet ${ }^{20}$. ¿Qué decir entonces de nuestro arcediano don Pedro? ¿Podemos decantarnos afirmativa o negativamente sobre su condición de monje a partir de los datos que conocemos de su vida? Trataremos de responder a esta cuestión una vez que hayamos intentado esclarecer cuál fue su procedencia.

\section{EN TORNO A SU LUGAR DE ORIGEN: ¿BOURGES O BÉZIERS?}

Las dos fuentes documentales más antiguas que aluden al lugar de origen de nuestro obispo proceden de Toledo y Osma, es decir, de los dos ámbitos en donde transcurrieron sus años de servicio a la Iglesia de Castilla. Cronológicamente hablando, ambas fuentes le sobrepasan en más de un siglo. La más importante, sin lugar a dudas, es De rebus Hispaniae (libro VI, capítulo 26), del arzobispo Rodrigo Jiménez de Rada (1170-1247), también conocido como el Toledano, tal vez el más relevante e influyente cronista latino de la España medieval. En su repertorio de eclesiásticos francos reclutados por don Bernardo hace una lacónica pero valiosa alusión a nuestro personaje, al que ya reconoce su elevatio a los altares:

${ }^{16}$ La abadía de Moissac, entre Agen y Toulouse, fue reformada por los cluniacenses en 10471048. A través de ella, Cluny comenzó a ser un factor importante en la región tolosana; CowDREY, H. E. J., The Cluniacs and the Gregorian Reform, Oxford, 1970, pp. 113-118.

17 «De Moysiaco duxit beatum Giraldum, quem prius cantorem in ecclesia Toletana, postea fecit archiepiscopum Bracarensem»; XIMENEZ dE RAdA, Historia de rebus Hispania, lib. VI, cap. XXVI, p. 210, lín. 29- 30; más extensa es la noticia dada por su biógrafo BeRnARDo DE CoImBRA, Vita beati Geraldi, en Portugaliae Monumenta Historica, Scriptores I, Lisboa, 1856, p. 54.

18 Aunque sobre la organización primitiva del cabildo toledano no han quedado suficientes huellas, es probable que la vida regular siguiese un modelo inspirado en la regla benedictina, en su interpretación cluniacense, dada la formación y la trayectoria del arzobispo Bernardo. Todo ello debió repercutir, además, en la solemnidad litúrgica catedralicia; Lop Otín, M. J., «El siglo XII en la historia del Cabildo Catedral de Toledo", en IzQuiERdo Benito, R. - Ruiz Gómez, F. (Coords.), Alarcos 1195, Actas del Congreso Internacional Conmemorativo del VIII Centenario de la Batalla de Alarcos, Cuenca, 1996, pp. 476-477. Me he ocupado de este tema en RuBIO SADIA, J. P., Las órdenes religiosas y la introducción del rito romano en la Iglesia de Toledo, Toledo, 2004, pp. 80-88.

19 Así sucede, por ejemplo, en la obra clásica de Defourneaux, M., Les Français en Espagne aux XP et XIle siècles, Paris, 1947, p. 37; o más recientemente en BARRAL I ALTET, X., «Observacions sobre les relacions historiques i artistiques entre Cluny i la Península lbèrica (segles X-XII)», Anuario de Estudios Medievales 24 (1994), p. 933.

20 Para este autor solamente Bernardo de Toledo, Dalmacio de Compostela y Geraldo de Braga pueden ser calificados como cluniacenses stricto sensu; HENRIET, P., «Un bouleversement culturel. Rôle et sens de la présence cléricale française dans la Péninsule Ibèrique (XIe-XIle siècles)», Revue d'Histoire de l'Église de France 90 (2004), p. 69 y nota 17. 
De Bituricis [Bernardus duxit] sanctum Petrum, quem prius archidiachonum Toletanum, postea fecit episcopum Oxomensem ${ }^{21}$.

En sentido estricto, Jiménez de Rada no dice que Pedro fuera natural de Bourges, sino que don Bernardo lo trajo desde allí (de Bituricis [duxit]). De su sucesor don Raimundo, en cambio, sí afirma que era oriundo de La Sauvetat (qui fuit oriundus de Saluitate). El primitivo nombre de Bourges, capital del actual departamento de Cher, era Avaricum (existente tal vez desde el siglo VII a. de C.), pero en los itinerarios de la época de Augusto se ve ya reemplazado por Bituricae, Biturigae, Bituriae, Betorgas, etc., de donde procede el nombre moderno ${ }^{22}$. Algunos autores han interpretado Bituricis en un sentido territorial, indicando la región de Berry/Berri23, donde habitaban los biturigos/bituriges; también se alude de forma imprecisa a «la Ciudad de Berri, que en Latin llaman Bicturicas» ${ }^{24}$. Sin embargo, consideramos que Bourges sigue siendo la interpretación más exacta.

Ahondando en la cuestión, podemos preguntarnos: ¿de qué material cronístico dispuso el Toledano para la redacción de De rebus Hispaniae VI, 26? Es evidente que no tenemos una respuesta apodíctica. Nada de esto se contenía en las crónicas de Lucas de Tuy, Pelayo de Oviedo o en la Najerense, fuentes habituales de Jiménez de Rada. Bernard F. Reilly ${ }^{25}$ ha propuesto una hipótesis verosímil: don Rodrigo pudo conocer el relato sobre el conflicto de don Bernardo con el primer cabildo de Toledo y el consiguiente reclutamiento de clérigos francos a través de fuentes legendarias o juglarescas del ámbito local, hoy perdidas. En concreto, pudo disponer de una vita o gesta del arzobispo Bernardo, dada la coherencia temática de esta sección y su género literario. Estos materiales constituirían el eslabón de la cadena que une el texto del Toledano con los hechos históricos de la llegada de Pedro y sus compañeros a la Iglesia primada.

En el ámbito oxomense, a su vez, encontramos lo que se ha dado en llamar Vita sancti Petri Oxomensis. A decir verdad, lo que ha llegado a nosotros son las lecturas del oficio de Maitines para la fiesta litúrgica del patrón de la catedral y la diócesis (celebrada el 2 de agosto), tal y como se conservan en un breviario romano-diocesano del siglo XV (Burgo de Osma, Biblioteca Capitular, manuscrito

21 Ximenez de Rada, Historia de rebus Hispanie, lib. VI, cap. XXVI, p. 210, lín. 29-31. Un poco después vuelve a citarlo a propósito de don Raimundo, el sucesor de don Pedro: «Et Raymundum, qui fuit oriundus de Saluitate, et fecit eum post beatum Petrum episcopum Oxomensem, qui postea inmediate successit eidem in ecclesia Toletana».

22 Gandilhon, A., «Bourges (Ville)», en Dictionnaire d'Histoire et de Géographie Ecclésiastiques, t. X, col. 178.

23 Así lo consideran, entre otros: PISA, F. DE, Descripcion de la Imperial Civdad de Toledo, Toledo, 1605 (ed. facsímil, Toledo 1974), lib. III, cap. xxVI, f. 162; y YEPES, A. DE, Crónica General de la Orden de San Benito, Patriarca de religiosos, t. VI, Valladolid, 1617, f. $381^{\mathrm{V}}$. En el mismo lugar, el benedictino refiere el error de algunos historiadores españoles que hacen a don Pedro natural de Vitoria (Álava) por haber confundido Bituricensse con Victoriensse.

24 Argálz, G. DE, La soledad laureada por San Benito y sus hijos en las Iglesias de España y Teatro monástico de la provincia Cartaginense, Madrid, 1675, f. 292 .

${ }^{25}$ ReILly, B. F., «El reinado de Alfonso VI de León y Castilla, de Rodrigo Jiménez de Rada, en el De rebus Hispaniae; metodologia histórica en el siglo XIII», Toletum, 2a época, 23 (1989), pp. 145-146. 
$2 \mathrm{~B})^{26}$, conocido como breviario de Montoya. Dichos textos fueron editados por François Plaine ${ }^{27}$, quien en su breve nota introductoria indicaba dos claves hermenéuticas interesantes: 1) La Vita fue escrita por alguien casi contemporáneo al santo, probablemente un canónigo; 2) La adaptación posterior para el uso litúrgico pudo comportar la supresión parcial del texto original. Así pues, el proceso se iniciaría con una Vita primitiva, un texto confeccionado por el propio clero oxomense, según Pérez-Embid, entre la segunda mitad del siglo XII y primera del XIII, en orden a lograr la estabilización institucional, mediante la glorificación de su primer patrón ${ }^{28}$. Un segundo paso fue el utilizar parte de dicho texto para la conmemoración litúrgica. Finalmente, Plaine ha reconstruido la Vita con el texto conservado en el oficio litúrgico, como acabamos de decir. Añadamos que el erudito benedictino denominó Vita posthuma S. Petri oxomensis a las lecturas del oficio de la Octava, que se encontraban a continuación en el mismo breviario ${ }^{29}$, y que son una colección de miracula post mortem, un «apósito posterior a la vita, fundado en la tradición piadosa», con un claro influjo silense ${ }^{30}$. La referencia que hallamos sobre el origen de don Pedro es similar a la anterior:

Venerabilis igitur antistes et prius pastor Petrus, natione Bituricensis, parentibus christicolis, cum esset bonae indolis adolescens, inter scholares diligenter invigilans, in lege Domini die ac note meditabatur ${ }^{31 .}$

Notemos únicamente que aquí sí se precisa que Pedro era bituricense o biturigo de nacimiento o, lo que es lo mismo, oriundo de la villa de Bourges. Esto concuerda también con un tercer documento, bastante más tardío y de valor inferior, que tiene por título Nomina Illustrium Virorum Episcoporum Oxomensis Ecclessiae. Se trata de un episcopologio latino de los siglos XV-XVI, conocido a través de Gregorio de Argáiz, al que denomina Catálogo antiguo de esta Santa Iglesia y abarca cincuenta prelados entre los años 590 y $1582^{32}$. En él comprobamos de nuevo el mismo dato que en los dos textos primitivos:

Interpositivo vero multo tempore, post terram ocupatam a sarracenis et quasi post trecentos annos recuperatam a xristianis, et illis temporibus regnante Alde-

26 Rojo Orcajo, T., «Catálogo descriptivo de los Códices que se conservan en la Santa Iglesia Catedral de Burgo de Osma», Boletin de la Real Academia de la Historia 94 (1929), p. 691.

27 Plaine, Fr. (ed.), "Vita S. Petri Oxomensis episcopi in Hispania ab anonymo suppari conscripta», Analecta Bollandiana 4 (1885), pp. 11-19.

28 PÉrez-EMBid WamBA, J., Hagiología y sociedad en la España medieval. Castilla y León (siglos XIXIII), Huelva, 2002, pp. 153-159.

29 Plaine, «Vita S. Petri», pp. 19-29.

30 PÉrez-Embid Wamba, Hagiología y sociedad, pp. 159-165. Tengamos en cuenta la hermandad entre el cabildo oxomense y la abadía de Silos, que se remonta al año 1132; MATÉ SAdoRNIL, L., "Hermandad entre el cabildo de Osma y el monasterio de Silos: creación de una geografía espiritual», (Memoria Ecclesiae 27), Oviedo, 2005, pp. 605-620.

31 Plaine, «Vita S. Petri», p. 12, núm. 3.

32 Portillo Capilla, T., Instituciones del Obispado de Osma, Soria, 1985, pp. 33-34; ID., «Fray Gregorio de Argáiz, O.S.B.: Memorias de la Santa Iglesia y Obispado de Osma... (1660)», Celtiberia 52 (2002), p. 144. 
fonso Rege, et tempore Bernardi archiepiscopi toletani, era Millessima C.XL.II, rexit Ecclesiam oxomensem PETRUS EPISCOPUS natione bitucicensis (sic), prius archidiaconus toletanus $[\ldots]^{33}$.

Por último, dando un salto en el tiempo, debemos señalar también que los bolandistas, en su célebre y monumental obra Acta Sanctorum ${ }^{34}$, no varían el dato más antiguo, ni en el comentario previo ni en la relación oficial de los hechos del santo o Acta, que copian del Martirologio de Tamayo de Salazar, como veremos en el apartado siguiente:

[COMMENTARIUS PRAEVIUS] Fuisse Petrum Gallum natione, Biturigibus oriundum, venisse in Hispaniam vocatum a beato Bernardo, qui tum abbas erat Sahaguntensis coenobii, postea archiepiscopus Toletanus ${ }^{35}$.

[ACTA] Petrus in Gallia Celtica apud Bituricos natus ${ }^{36}$.

Como complemento a esta escueta noticia, merece la pena señalar un dato referente a la realidad eclesial de Bourges en aquella época. Es llamativa la riqueza de la vida canonical existente por entonces en aquella ciudad; además del cabildo catedralicio de San Esteban, que llevaba vida comunitaria, había otros, en su mayoría regulares: Nuestra Señora de Sales, Nuestra Señora de Montermoyen, San Oûtrille du Château, San Pedro-le-Puellier o San Ursin,o bien la abadía de San Ambrosio, un importante convento de canónigos agustinianos, que llegó a contar con cuatro prioratos ${ }^{37}$. Es un hecho a tener en cuenta, pese a que ningún dato relaciona directamente a don Pedro con alguno de estos centros religiosos.

Ahora bien, a pesar de que los textos mencionados no presentan dudas en relación con la patria de don Pedro, algunos historiadores, en especial franceses, disienten al respecto. En efecto, nuestro prelado figura como procedente de Béziers, ciudad situada a unos $25 \mathrm{kms}$. al nordeste de Narbona, en el departamento actual de Hérault (Languedoc- Roussillon). Creemos que el principal difusor de esta postura ha sido Marcelin Defourneaux con una monografía publicada en 1947 y convertida en obra de referencia para cuantos profundizaban en la penetración francesa en suelo peninsular durante la plena Edad Media ${ }^{38}$. Desde entonces, Pierre de Béziers sigue apareciendo en artículos menores ${ }^{39}$, e incluso en obras de gran relevancia, como la de Andrés Gambra, quien cita explícitamente a Defourne-

33 Portillo Capilla, Instituciones, p. 341.

34 Acta Sanctorum, Augusti, t. I, Paris-Roma, 1867, pp. 189-194.

35 Idem, p. 189C.

36 Idem, p. 192B.

37 Gandilhon, A., «Bourges (Ville)», Dictionnaire d'Histoire et de Géographie Ecclésiastiques, t. X, cols. 179-186.

38 Defourneaux, M., Les Français en Espagne, p. 36. La referencia no está sujeta a equívocos: «De Béziers vint Pierre qu'il [=Bernardo de Toledo] nomma archidiacre de Tolède et qui devint ensuit évêque d'Osma».

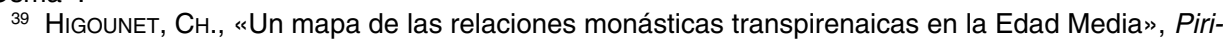
neos 7 (1951), p. 545; el original francés en Revue de Comminges 64 (1951), pp. 129-138; FonDA, J., «Bernard de La Sauvetat, évêque de Sigüenza», Revue de l'Agenais (1969), p. 168. 
aux ${ }^{40}$. En cualquier caso, ninguno de estos autores aduce argumentación alguna para probar su postura, ni hace alusión al criterio mayoritario. La única fuente citada por Defourneaux es De rebus Hispaniae, por lo cual la hipótesis de Béziers podría haber estado originada por un error de traducción; un error antiguo si nos fijamos en el texto castellano de la Primera crónica general de España, compuesta entre 1270 y 1280 :

De Beders trexo a don Pedro que fizo arcediano de Toledo, et despues obispo de Osma; despues fue santo, et dizenle sant Pedro de Osma ${ }^{41}$.

La deformación del término podría tener su explicación en la semejanza de los topónimos latinos, de idéntica raíz: Bit-uricensis I Bit-errensis. En resumen, debemos reconocer que no hallamos ningún argumento de índole histórica que nos permita vincular el origen de Pedro de Osma con la ciudad de Béziers.

\section{¿DON PEDRO DE OSMA ERA CLUNIACENSE?}

En la actualidad es ampliamente aceptado que Pedro de Osma fue monje. El dato ha sido incorporado, como hemos visto, al propio Martirologio Romano. Es más, un simple repaso a la historiografía de las tres últimas décadas nos puede cerciorar sobre ello ${ }^{42}$. Comencemos reconociendo que el caso no es insólito; algo similar ha sucedido, por citar un ejemplo, en la vecina Iglesia de Segovia con su primer obispo francés, don Pedro de Agen (1120-ca.1148), en quien se ha visto a otro de los cluniacenses importado por don Bernardo ${ }^{43}$, pese a que tampoco cons-

40 Gambra, A., Alfonso VI: Cancillería, curia e imperio. Vol. I: Estudio, (Fuentes y Estudios de Historia Leonesa 62), León, 1997, p. 653.

41 Meméndez PIDAL, R. (ed.), Primera crónica general de España, Madrid, 1955, t. II, p. 544.

42 Las numerosas publicaciones de Portillo Capilla han realizado una notable difusión de esta idea: Portillo Capilla, Instituciones, p. 37; ID., Catálogo del Archivo Diocesano del obispado de Osma-Soria, Burgo de Osma, 1981, p. 158; ID., «La regla de San Agustín en la Catedral de Santa María de Osma», en Aniz IRIARTE, C. - Díaz MARtín, L. V. (coord.), Santo Domingo de Caleruega. Contexto eclesial religioso, IV Jornadas de Estudios Medievales, Salamanca, 1996, p. 226; ID., «Santoral hispanomozárabe de la Diócesis de Osma-Soria», (Memoria Ecclesiae 3), Oviedo, 1992, p. 207; ID., «Vida administrativa en las catedrales en los siglos XII al XVI», (Memoria Ecclesiae 4), Oviedo, 1993, pp. 85-86; ID., «Retablo histórico de la diócesis de Osma», en La ciudad de los seis pisos, catálogo de la exposición Las Edades del Hombre, El Burgo de Osma-Soria, 1997, p. 36. Pero también se halla en LinAGE CondE, A., Los orígenes del monacato benedictino en la Peninsula Ibérica, t. II, León, 1973, p. 968; VILLAR GARCíA, L. M., La Extremadura castellano-leonesa. Guerreros, clérigos y campesinos (711-1252), Valladolid, 1986, p. 210; Gambra, A. Alfonso VI: Cancillería, curia e imperio. Vol. I: Estudio, p. 653; Maté Sadornil, «Hermandad», p. 607. Otros no lo afirman con total certeza pero lo suponen: «No se conoce el origen y calidad de todos estos personajes, pero es probable que todos o casi todos eran monjes»; PÉREZ DE URBEL, J., Los monjes españoles en la Edad Media, II, Madrid, 1934, p. 431. Por el contrario, Reglero de la Fuente ya no lo sostiene en Reglero de LA Fuente, C. M., «El obispado de Osma hasta mediados del siglo XIII: Génesis y problemática», en ANIz IRIARTE, C. - DíAz MARTín, L. V. (coord.), Santo Domingo de Caleruega Contexto eclesial religioso, IV Jornadas de Estudios Medievales, Salamanca, 1996, p. 186.

43 LINAGE CONDE, A., «La donación de Alfonso VI a Silos del futuro priorato de San Frutos y el problema de la despoblación», Anuario de Historia del Derecho Español 41 (1971), p. 990; VILLAR GARCíA, L. M., La Extremadura castellano-leonesa, p. 210; PÉREz VillanueVA, J., «Repoblación de Segovia. Restauración de su obispado. Algunas cuestiones criticas», en Segovia 1088-1988. Congreso de Historia 
ta en la documentación ${ }^{44}$. Es verdad, debemos insistir en ello, que este tipo de afirmaciones tiene a su favor el contexto general de la penetración de Cluny en la Península, al que ya hemos aludido y, más concretamente, el hecho de que el arzobispo de Toledo, responsable de la principal oleada de clérigos francos, perteneciera al Ordo cluniacensis. No olvidemos tampoco que el abad san Hugo aconsejó por carta a Bernardo que nutriera el cabildo toledano con «sabia» cluniacense (nostre ordinis professores) ${ }^{45}$.

Volviendo a nuestra indagación sobre la supuesta profesión monástica de don Pedro, el primer dato significativo lo tenemos en el silencio que guardan al respecto tanto De Rebus Hispaniae como la Vita sancti Petri Oxomensis. Nada vemos en ninguna de estas dos fuentes que confirme semejante hipótesis. Igualmente revelador es el silencio de las dos crónicas anónimas de Sahagún, que narran la historia del cenobio leonés desde finales del siglo XI hasta mediados del XIII' ${ }^{46}$ En el ámbito del Toledo renacentista, por su parte, tampoco hallamos ninguna referencia en esta línea: ni Pedro de Alcocer (s. XV-XVI) ${ }^{47}$, ni Francisco de Pisa (15341616), en su apartado titulado De San Pedro Arcediano de Toledo, Obispo de Osma ${ }^{48}$, van más allá de los datos fundamentales (origen francés, arcedianato en la Iglesia primada y pontificado en Osma). Pisa refiere, además, otros aspectos de interés, a saber, que en las lecturas de los breviarios medievales de Toledo ${ }^{49}$ y Osma se contenía la Vita («se haze mencion de su vida santa y ejemplar»), y que san Pedro era titular de una capilla en la catedral de Toledo.

Así pues, hemos de esperar a la historiografía barroca para empezar a ver alusiones a su condición monástica. El fecundo y poco crítico Gil González Dávila (ca.1578-1658) escribe que fue San Orencio de uuch $^{50}$ el primer monasterio de don

de la Ciudad, Actas, Segovia, 1991, p. 189; VV.AA., Segovia cisterciense. Estudios de historia y arte sobre los monasterios segovianos de la orden del Cister, Segovia, 1991, pp. 26 y 241; GARCía HERNANDO, J., «Apuntes para la historia de la diócesis de Segovia», Estudios Segovianos 22 (1970), p. 120; ID., "Segovia, Diócesis de», Diccionario de Historia Eclesiástica de España, t. IV, p. 2393; SANZ y SANZ, H., «Riqueza documental y bibliográfica del Archivo de la Catedral de Segovia», Estudios Segovianos 28 (1976), p. 140.

44 BARTolomé Herrero, B., «Obispos extranjeros al frente de la Diócesis de Segovia (1120-1742)», Estudios Segovianos 48 (2005), p. 25-28.

45 El texto latino de la carta se encuentra en Rivera Recio, J. F., La Iglesia de Toledo en el siglo XII (1086-1208), vol. I, Roma, 1966, pp. 68-69, nota 16. La traducción parcial en: ID., La Iglesia de Toledo en el siglo XII (1086-1208), vol. II, Toledo, 1976, pp. 21-22.

${ }_{46}$ La crónica que data del siglo XII se encuentra en: PUYOL Y ALONSO, J., «Las crónicas anónimas de Sahagún», Boletín de la Real Academia de la Historia 76 (1920), pp. 7-26, 111-122, 242-257, 339-356, 395-419, 512-519; 77 (1921), pp. 51-59, 151-161; la del siglo XIII en: 77 (1921), pp. 162-192.

47 Alcocer, P. DE, Hystoria, o descripción de la Imperial cibdad de Toledo, Toledo, 1554 (ed. facsímil: Toledo, 1973), lib. I, cap. LXXI, f. $57^{\mathrm{V}}$.

48 PISA, Descripcion, lib. III, cap. XXVI, f. 162.

49 Así aparece, por ejemplo, en el breviario manuscrito 33.9 de la Biblioteca Capitular de Toledo (siglo XV). La distribución de la Vita en el oficio de Maitines (f. 427) es la siguiente: lectio l=Vita 3, lín. 1-4 [ed. de PlAINE]; lectio II=Vita 3, lín. 4-9; lectio III=Vita 4, lín. 1-7; lectio IV=Vita 4, lín. 7-10; lectio V=Vita 5, lín. 1-5; lectio VI=Vita 5, lín. 5-11. Se trata de una lectio continua de los núms. 3 al 5 , en los que se recogen los datos históricos fundamentales de la vida de san Pedro.

50 Fundado en el siglo X, fue dado a Cluny en 1068 por el conde Aimeric de Auch y su hermano Bernardo, llegando a ser un priorato de la gran abadía borgoñona; CoWDREY, The Cluniacs, pp. 97-101; VALous, G. DE, Le monachisme clunisien des origines au XV siècle, t. II, París, 1970, p. 208. 
Pedro, pasando posteriormente al de Sahagún. Tal vez la intención no es otra que mostrar una perfecta comunidad de origen y de escuela entre Bernardo de Toledo y su sobrino Pedro de Osma:

Siguio las armas san Pedro siendo moço, y ya mas hombre, licuado del espirito diuino, desamparò la milicia, y siguio otra con que se adquieren mas importantes Reynos, y coronas, tomando el habito del gran Padre san Benito en el Conuento Auriacense, en la Ciudad de Aux, donde viuio algunos años, hasta que el Rey don Alonso el Sexto reedificando el Monasterio de Sahagun [...], embiò a pedir al Abad Cluniacense le embiasse Monges, que con su exemplo y vida, consiguiesse el fin que desseaua, fue el escogido Bernardo, que traxo consigo a su sobrino san Pedro, y otros santos Varones, que ilustraron con sus vidas las Iglesias que rigieron ${ }^{51}$.

Del mismo modo, los autores benedictinos Prudencio de Sandoval (ca.15511620) y Antonio de Yepes (1554-1618) destacan como principales partidarios de ver a Pedro como profeso de Sahagún. Según ellos, su condición de benedictino quedaba fuera de toda duda. La problemática residía más bien en dilucidar si vino desde Francia a Sahagún siendo ya monje, como creía González Dávila, o si vistió el hábito de san Benito por vez primera en el cenobio leonés. Así lo expresa el mismo padre Yepes:

De que san Pedro de Osma aya sido monge de la Orden de san Benito, nunca los autores han puesto duda en ello, y basta que fue Arcediano de Toledo, en tiempo que los monges seruian à aquella santa Iglesia, para que esta verdad quede por cierta. La dificultad no esta sino en saber, si san Pedro vino monge ya de Francia, como san Giraldo [...], o si tomo el abito en san Benito el Real de Sahagun. Yo me inclino mas à este segundo modo de dezir, porque assi es publico en la tradicion de aquella santa casa, y he visto algunas memorias della, en que se refiere, que san Pedro de Osma era sobrino del Arçobispo don Bernardo, y que le traxo à España, a que tomasse el abito en san Benito de Sahagun, deste parecer es el Obispo de Pamplona fray Prudencio de Sandoual, en la historia que escriuio de Sahagun capitulo veinte y tres $[\ldots]^{52}$.

Para Yepes el dato irrefutable que demuestra su pertenencia a la Orden benedictina es el haber ejercido como arcediano de Toledo, en un momento en el que eran monjes - según cree- todos los que servían en esta Iglesia. Este pan-cluniacismo, del que Yepes es un claro exponente ${ }^{53}$, se puede apreciar todavía un siglo más tarde en Francisco de Berganza $(1663-1738)^{54}$. Sin embargo, ya en la se-

51 GonzÁlez DÁVILA, G., Theatro eclesiastico de las ciudades, e Iglesias Catedrales de España. Vidas de sus Obispos, y cosas memorables de sus Obispados, t. I, Salamanca, 1618, pp. 20-21.

52 YePES, Crónica General, t. VI, ff. 381-382.

53 Sobre su tendencia a vestir el hábito de su Orden a santos y personajes egregios puede verse CoLomBÁs, G. M., La tradición benedictina. Ensayo histórico. Vol. VII, 2: Los siglos XVII y XVIII, Zamora, 1998, pp. 692-693.

54 «Mas no solo San Giraldo, San Pedro de Osma, y Mauricio fueron Monges Cluniacenses, sino los demas, que traxo el Arçobispo Don Bernardo para componer el Cabildo de Toledo»; BERGANZA, F. DE, Antigüedades de España. Primera parte, Madrid, 1719 (ed. facsímil: Burgos, 1992), p. 467. 
gunda mitad del siglo XVIII se alzan voces críticas hacia esta interpretación. De hecho, Romualdo de Escalona la rebate, en su Historia de Sahagún, con un párrafo que denota mayor equilibrio y una mayor fidelidad a las fuentes:

Muchos Historiadores dicen, que todos estos Obispos eran Monges Benitos, y que despues de venir de Francia, fueron Monges en esta Casa [=Sahagún]. No hay duda, que daría no poco honor á la Religion de San Benito, y á este Monasterio el que esto fuera así; pero los que lo dicen no dan pruebas sólidas de su dicho, ni tampoco las tengo yo mejores para negarlo. Es muy creible que lo fueran por lo menos algunos, y que D. Bernardo se valiera de sugetos, que tenia tratados en los Monasterios de su pais. Tarnbien parece regular, que al volver á su Iglesia se pasara por este su Monasterio con sus compañeros; y que si algunos eran mozos aún los dexara aquí por algun tiempo: pero nada de esto hallamos asentado en los papeles de aquel tiempo ${ }^{55}$.

En segundo lugar, respecto a la pregunta sobre dónde inició san Pedro su vida monástica, Yepes, al igual que Sandoval y Escalona, afirma que fue en Sahagún. Las razones que aduce son dos: de un lado, la creencia tradicional existente en el propio cenobio leonés y, de otro, unas inciertas «memorias» que dice haber visto allí, acerca de las cuales nada especifica. Decimos que son inciertas porque Escalona, monje de Sahagún, escribe que «solo hay tradición de que fué Monge aquí S. Pedro de Osma» y esa tradición se apoya en el más que dudoso «Leccionario de la Iglesia de Astorga, que trae Tamayo» ${ }^{56}$. Por su parte, el también benedictino Gregorio de Argáiz (ca.1598-1679) resta importancia al debate Auch-Sahagún como primera escuela monástica de Pedro. Para él, lo esencial radica en que realmente fue conventual de Sahagún. Eso sí, tampoco aquí se aportan pruebas concluyentes:

[Don Pedro] era sobrino del Arçobispo de Toledo Bernardo de Agen. Traxole consigo de Francia. Unos dizen, que Monge; otros dizen, que mancebo seglar, y que le diò el habito de san Benito en Sahagun, donde al presente era Abad antes que se ganara Toledo, y saliera por Arçobispo. Importa poco el aueriguar esta circunstancia del tiempo de su Monacato; pues basta saber, que viviò, y fue Monge Conventual de san Benito de Sahagún. Criase con grande obseruancia, conforme la Reformacion Cluniacense, que pocos años antes auia entrado en Sahagun ${ }^{57}$.

Es así como se va afianzando entre los historiadores del Barroco, en especial benedictinos, la convicción de un Pedro de Osma sobrino de don Bernardo y monje de Auch y/o de Sahagún; dos datos, en definitiva que no habíamos detectado en ninguna de las fuentes anteriores. Toda esta corriente historiográfica alcanza su punto álgido con el controvertido Martyrologium Hispanum ${ }^{58}$ de Juan Tamayo de Salazar (†ca.1662). Una obra, en efecto, que ha merecido el calificativo

55 Escalona, R., Historia del Real Monasterio de Sahagún, Madrid, 1782 (ed. facsímil: León, 1982), lib. II, cap. VIII, § 8, p. 87.

56 Ibídem.

57 ARgÁlz, La soledad laureada, f. 292 .

58 El título completo de la obra es: Anamnesis, sive Commemorationis Sanctorum hispanorum, Pontificum, Martyrum, Confessorum, Virginum, Viduarum, ac Sanctarum Mulierum, ad ordinem, et methodum Martyrologii Romani, quo utitur Ecclesia Catholica, 6 t., Lugduni, 1651-1659. 
de «monstruosa» de la pluma del jesuita García Villada ${ }^{59}$, y los juicios implacables de Godoy Alcántara ${ }^{60}$. Tamayo, que dice servirse de un manuscrito de Astorga, de dudosa antigüedad ${ }^{61}$, sigue la opinión de González Dávila sobre los comienzos en la abadía cluniacense de Auch:

Tunc quid agendum quaeritans [Petrus], S. Benedicti ordinem tota viscerum compage suspirans, calcatis innumerabilibus contradictionis ambagibus, in Auricensi Coenobio cucullam induit. Ibidem S. Vir per aliquos annos Monachum egit, donec Rex Alphonsus Castellae, qui Toletum cepit, Sahaguntinense Monasterium reaedificare constituit, illudque totius Regni caput inter caetera destinare ${ }^{62}$.

Aunque conoce las obras de Yepes, Sandoval y Hugo Menardo, y las cita como prueba sólida de que Pedro fue Monachus Clunincensis, se muestra partidario de su profesión en Auch, sin aducir pruebas (sed veriorem credo, quam Acta referunt $^{63}$. Sin embargo, lo más importante a propósito de este singular autor es que los Acta S. Petri Uxamiensis de su Martirologio fueron transcritos ad pedem litterae en la magna obra de los bolandistas (Acta Sanctorum), favoreciendo, de este modo, una difusión de alcance universal, con el aval de poseer una depuración crítica. Eso sí, dado que el término «Auricensi coenobio» podía prestarse a equívocos, Du Solier, el autor bolandista firmante del artículo sobre san Pedro (De S. Petro episcopo confessore Oxomi seu Uxamae in Hispania) hace la precisión siguiente:

Pro Auricensi malim legere Auscense vel Auxitanum, in quo Bernardus monachus fuerit, ac S. Petrum infla vocet Bernardi professione filium, dubium non videtur, quin ad idem coenobium uterque pertineat ${ }^{64}$.

Teniendo en cuenta la similitud entre Auri-censis y Aflri-liacensis era fácil vincular a don Pedro con el monasterio de Aurillac (Auvernia) ${ }^{65}$. Tal vez por ello Du Solier consideró que era preferible sustituirlo por Auscense o Auxitanum, términos que reflejaban con más exactitud la pertenencia a Auch. Con todo, el conjunto de

59 García Villada, Z., Historia eclesiástica de España, t. I/1, Madrid, 1929, p. 12.

60 «Era este Tamayo tan terrible partidario de los cronicones como su homónimo el de Várgas, infelicísimo latino, creyéndose todo lo contrario, áulico de Ramirez de Prado, supersticioso, embustero [...]. Dióle principalmente nombre un martirologio, hecho en modo de los cronicones, esto es, legitimando santos litigiosos ó desacomodados, cambiándoles las circunstancias de su vida y aplicándoles inscripciones gentílicas más ó menos supuestas, todo ello apoyado en la fe de manuscritos que decía poseer [...]»; y en nota añade, a propósito del Martirologio, que era la obra que le proporcionó mayor fama «y su principal depósito de ficciones, errores y mentiras»; Godoy AlcÁNTARA, J., Historia de los falsos cronicones, Madrid, 1868, pp. 237-238.

${ }_{61}$ Es cuestionada su antigüedad en Biblioteca hagiographica latina Antiquae et Mediae AEtatis, vol. II, (Subsidia Hagiographica 6), Bruxelles, 1900-1901 (reimpr. 1949), p. 983.

62 Tamayo de SalazaR, J., Martyrologium Hispanum, t. IV, Lugduni, 1656, p. 342.

63 Idem, p. 345.

64 Acta Sanctorum, Augusti, t. I, París-Roma, 1867, p. 194.

65 PÉrez-EMBID WAMBA, Hagiología y sociedad, p. 154, nota 43. Adviértase que la paginación de Loperráez dada por este autor no es exacta, siendo la correcta la p. 84. Esta abadía, fundada por el conde san Geraldo en el paso del siglo IX al X, había adoptado, al igual que Auch, las costumbres y el espiritu de Cluny en tiempos del abad Arnulfo, a mediados del siglo X; FonTAINE, P., "Aurillac», Dictionnaire $d$ 'Histoire et de Géographie Ecclésiastiques, t. V, col. 758; VAlous, Le monachisme clunisien, p. 180. 
la narración de Tamayo no se prestaba a equívocos, porque Pedro, además de ser considerado sobrino de Bernardo (eius secundum carnis vinculum Nepotem), era «hijo» suyo por profesión (merito professione Filium) ${ }^{66}$, equivalente a decir monje de Auch. Ante semejante evolución de los hechos, dom Plaine mostraba cierto malestar viendo cómo la primitiva Vita S. Petri era escasamente conocida por los bolandistas y lo era sólo a través de la obra de un autor tan amigo de ficciones como Tamayo de Salazar ${ }^{67}$.

No hay duda, pues, de que la influencia ejercida por el texto de los Acta Sanctorum entre los historiadores contemporáneos ha sido muy amplia. Sirva de ejemplo la voz que le dedica a don Pedro el Diccionario de Historia Eclesiástica de España ${ }^{68}$. La incoherencia de la noticia, a nuestro parecer, no es sino fruto de dicho influjo: mientras que, por una parte, se afirma que «no existen más fuentes para la vida del santo que la Vita et miracula, escrita para el leccionario de Osma y de Palencia», por otra, se dice que don Pedro «ingresó en la abadía de Saint-Orens de Auch (Francia), dependiente de la de Cluny», dato que, como hemos visto, está ausente en la Vita. En definitiva, a la pregunta sobre la condición monástica de nuestro santo prelado sólo encontramos una respuesta afirmativa en la producción historiográfica de los siglos XVII y XVIII, ya que las fuentes anteriores nada mencionan sobre este aspecto.

\section{CONCLUSIÓN}

Llegados al fin de nuestro estudio, debemos admitir que no tenemos motivos serios para dudar de la fiabilidad de las dos fuentes medievales (De Rebus Hispaniae y la Vita Sancti Petri Oxomensis), que nos remiten a Bourges como la patria del prelado que regló la Iglesia de Osma entre 1101 y 1109 . Esas dos fuentes entroncan directamente con los dos ámbitos castellanos (Toledo y Osma), en los que don Pedro desempeñó su responsabilidad de arcediano y obispo, respectivamente. Por el contrario, esos mismos documentos no nos permiten tener certeza de que nuestro prelado hubiera sido monje cluniacense, ni en Auch (o Aurillac), ni en Sahagún. En otras palabras, las fuentes primitivas no niegan la creencia tradicional, simplemente no la consignan. Todo ello induce a pensar que la base sobre la que se sustenta dicha opinión, por generalizada que esté y aun siendo verosímil, es a nuestro parecer poco fiable. Nos parece muy ilustrativo concluir estas páginas con un texto del canónigo Juan Loperráez, en el cual, al margen de la inexactitud en su cita de Fleury ${ }^{69}$, da muestras de unos criterios historiográficos que siguen teniendo plena vigencia en nuestros días:

66 Tamayo de Salazar, Martyrologium Hispanum, t. IV, p. 342.

67 Plaine, «Vita S. Petri», p. 11.

68 AldeA, Q., «Osma, Pedro de», en Diccionario de Historia Eclesiástica de España, t. III, p. 1849.

69 En realidad, el autor galo se limita a escribir: «En revenant, Bernard passa en France, où il choisit des hommes savans \& vertueux, \& de jeunes-gens dóciles, qu'il emmena en Espagne. De Moissac il tira Girauld [...]. De Bourges, Pierre qu'il fit archidiacre de Tolède, puis évêque d'Osma»; Fleury, M., Histoire Ecclésiastique, t. IX, Anismes, 1779, lib. 64, núm. 43, p. 435. 
Fleuri escribe que [...] tomó el hábito de San Benito en el Convento Auriacense, donde vivió hasta que el Arzobispo D. Bernardo lo traxo á España. Esta última noticia puede convenir con la que nos dan algunos de nuestros Autores diciendo, que tomó el hábito en uno de los Conventos de la refomación Cluniacense en Francia; pero sin darle nombre, y omitiendo la circunstancia de que siguió las armas. Sandoval en la historia que escribió de la fundacion del Convento de Sahagun, asegura que fué Monge en él, y que es conforme esta noticia con la tradicion inmemorial de aquel Monasterio. Yo dudo mucho de estos dos destinos, fundándome en que no hacen mencion de ellos los rezos del Santo antiguo ni moderno, ni el Arzobispo D. Rodrigo... ${ }^{70}$. 